\title{
Effects of Hydrogen Sulfide and Siloxane on Landfill Gas Utility Facilities
}

\author{
Sangchul Nam ${ }^{1}$, Kwang-Beom Hur ${ }^{2}$, Nam-Hoon Lee ${ }^{3 \dagger}$ \\ ${ }^{1}$ Department of Advanced Technology Fusion, Konkuk University, Seoul 143-701, Korea \\ ${ }^{2}$ Korea Electric Power Corporation (KEPCO), Daejeon 305-706, Korea \\ ${ }^{3}$ Department of Environmental Engineering, Anyang University, Anyang 430-714, Korea
}

\begin{abstract}
This study examined the emission characteristics of impure gas-like hydrogen sulfide and siloxane contained in landfill gas (LFG) and investigated the effect of impure gas on LFG utility facilities. As a result of an LFG component analysis from eight landfills in the same environment, hydrogen sulfide averaged $436 \mathrm{ppmv}(22-1,211 \mathrm{ppmv})$, and the concentration of total siloxane averaged $7.95 \mathrm{mg} /$ $\mathrm{m}^{3}\left(1.85-21.18 \mathrm{mg} / \mathrm{m}^{3}\right)$. In case of siloxane concentration by component, the ratio of D4 (average $\left.3.79 \mathrm{mg} / \mathrm{m}^{3}\right)$ and D5 (average $2.64 \mathrm{mg} /$ $\mathrm{m}^{3}$ ) indicated the highest level. Different kinds of scales were found on the gas air heater (GAH) and inside the boiler. The major component of scale from the $\mathrm{GAH}$ was $\mathrm{Fe}_{2} \mathrm{O}_{3}$ of $38.5 \%$, and it was caused by hydrogen sulfide. Other scale was found on the bottom and the wall of the boiler and the scale was silicon dioxide of $92.8 \%$ and $98.9 \%$. The silicon dioxide scale was caused by combustion of siloxane. As a result of a scanning electron microscopy analysis, the structure of the silicon dioxide scale from the boiler was an immediate filamentous type. Consequently, as silicon dioxide scale is bulky, such bad effects were worsening, as an interruption in heat conduction, increase in fuel consumption, damage to the boiler by overheating, and clogged emission pipeline could occur in LFG utility facilities.
\end{abstract}

Keywords: Effect, Hydrogen sulfide, Landfill gas, Siloxane, Utility facilities

\section{Introduction}

Due to the increase in energy cost by constantly high oil prices and the obligation to reduce greenhouse gases, the world is paying attention to renewable energy that can replace fossil fuels. Waste resources are recognized as a renewable energy source and are the most important alternative energy source from environmental and economic perspectives. In particular, biogas with the use of organic wastes not only has a greater possibility to be used as energy than other wastes but is also capable of controlling $\mathrm{CH}_{4}$ and $\mathrm{CO}_{2}$ discharge, which have a significant greenhouse effect [1,2]. Landfill gas (LFG) represents this biogas together with anaerobic digestion gas. Because LFG contains $40-60 \% \mathrm{CH}_{4}$ and $40-55 \% \mathrm{CO}_{2}[3,4]$, energy source-applied businesses have started in Europe and have been conducted dynamically since 1970 [5].

A method for producing heat and electricity through combined heat and power has been used most frequently with LFG as a resource [6, 7]. LFG is saturated with moisture, compared to other natural gases and contains various trace compounds, including hydrogen sulfide, siloxane, ammonia, and carbon monoxide [3, 8-10]. LFG performance is degraded and lifespan is reduced by impurities if it is used directly as a fuel in a utility facility that utilizes a boiler and generator. In particular, damage caused by siloxane and hydrogen sulfide scale is serious [11-13]. Various pretreatment processes to remove siloxane and hydrogen sulfide have been developed and commercialized to produce heat and electricity in Europe and the USA. However, as few studies have been conducted in Korea on the characteristics of generating siloxane and hydrogen sulfide in LFG and on the effect of their scale on LFG utility facilities, development of pretreatment processes is still insufficient.

In this study, the characteristics of siloxane and hydrogen sulfide concentrations in LFG were identified by focusing on landfills where LFG utility facilities are operated at present. Hydrogen sulfide and siloxane scale on LFG utility facilities was analyzed to apply basic data for developing a future pretreatment process.

\section{Materials and Methods}

\subsection{Landfills and LFG Utility Facilities}

The target landfill is S landfill, which was divided into zone A, in which the landfill had been completed, and zone B, in which

Received May 18, 2011 Accepted July 25, 2011

${ }^{\dagger}$ Corresponding Author

E-mail: nhlee@anyang.ac.kr

Tel: +82-31-467-0891 Fax: +82-31-467-0789 cc This is an Open Access article distributed under the terms of the Creative Commons Attribution Non-Commercial License (http://creativecommons. org/licenses/by-nc/3.0/) which permits unrestricted non-commercial use, distribution, and reproduction in any medium, provided the original work is properly cited. 


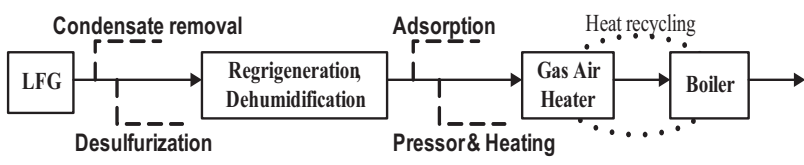

Fig. 1. Process outline of landfill gas (LFG) utility facilities of S landfill.

the land is being filled at present for a survey. It was determined that zone A began to be filled with municipal and industrial solid waste in 1992 and was finished in 2000. Zone B began to be landfilled in October 2000, is presently under landfill construction, and is being filled with municipal solid waste, office waste and building waste.

Scale occurring from biogas in utility facilities causes corrosion, abrasion, and clogging of equipment, resulting in excessive maintenance costs and reduced competitiveness [14, 15]. Fig. 1 shows the LFG utility facility process for S landfill to analyze the scale caused by biogas in utility facilities. Heat generated by LFG combustion passes through the heating surface and superheater of the boiler to produce superheated steam, which converts thermal energy into kinetic energy in a turbine system to operate a generator. At present, electricity is produced using a $50 \mathrm{MW}$ generator, which consumes LFG at about $500 \mathrm{~m}^{3}$ per minute. Various processes are applied such as removing condensing water, desulfurization, refrigeration, dehumidification, absorption, and heating and pressurization to remove moisture and hydrogen sulfide as an LFG pretreatment.

\subsection{Collection of LFG and Scale Sampling}

The sampling area was divided into zones A and B. Samples were collected at three gas sampling zones, whose landfill ages were different, and at a duct line where all LFG was collected to flow into the utility facilities. Four zones (total of eight zones) were designated for sampling. The characteristics of each zone are organized in Table 1.

Scale was found generally at the boiler and the gas air heater (GAH), so scale samples were collected. In the case of the boiler, scale was collected from the bottom and walls. Each sample was kept dry until analysis.

\subsection{LFG and Scale Analysis}

A portable instrument (LMSxi; Gas Data Ltd., Coventry, UK) was used to analyze the LFG components, and a value was acquired after LFG was passed sufficiently while measuring. Measurable components and the detection limit of each component were $\mathrm{CH}_{4}(\%), \mathrm{CO}_{2}(\%)$, oxygen (\%), nitrogen (\%), hydrogen sulfide (detection limit, 199 ppmv), and ammonia (detection limit, 5,999 ppmv).

Siloxane was collected using the impinger absorption method, which has higher precision and a 10 times lower detection limit than that of the canister method [16]. LFG was passed through the LFG flow-control pump and was then absorbed in four-layered impingers containing $6 \mathrm{~mL}$ of methanol absorption liquid $[15,17]$. A low temperature $\left(4 \pm 2^{\circ} \mathrm{C}\right)$ was maintained to increase the gas absorption rate, and flow was maintained at $100 \mathrm{~mL} / \mathrm{min}$. A wet gas meter was installed at the rear of the impinger and we re-checked whether the total amount of absorbed gas and discharge were maintained uniformly [15, 17]. Siloxane was analyzed using gas chromatography/mass spectroscopy (Shimadzu QP-5050; Shimadzu, Kyoto, Japan) [6, 18]. The sum of the concentrations of the seven materials ranging from L2-L5 to D4-D6 was used as the total siloxane value.

Scanning electron microscopy-energy-dispersive X-ray spectroscopy (JSM-6380; JEOL, Tokyo, Japan) analysis, elemental analysis (Finnigan Flash 1112 series; Thermo Finnigan, San Jose, CA, USA), and chemical composition analysis were implemented to investigate the scale composition and components.

\section{Results and Discussion}

\subsection{LFG Results}

Table 2 shows the analysis of the LFG component results for the target landfill. The $\mathrm{CH}_{4}$ concentration in LFG occurring at the landfill averaged $45.7 \%$ (range, $16.0-57.0 \%$ ) If zone A3 was excluded, it was $40-60 \%[3,4]$, which is a normal $\mathrm{CH}_{4}$ concentration to satisfy LFG recycling. The reason that the $\mathrm{CH}_{4}$ concentration in zone $\mathrm{A} 3$ was low was due to air inflow. The $\mathrm{CH}_{4}$ concentration of landfill A under the follow-up control averaged $42.9 \%$, showing a lower $\mathrm{CH}_{4}$ concentration than that of landfill $\mathrm{B}$, which is being filled at present.

As a result of analyzing other gases, the zone A2 ammonia was $375 \mathrm{ppmv}$, which was the lowest level, whereas that of zone A3 was 3,514 ppmv, the highest. Hydrogen sulfide was 22 ppmv at zone A2, the same zone as ammonia, whereas 1,211 ppmv was the highest level at zone B3. The pretreatment process for am-

Table 1. Landfill site descriptions

\begin{tabular}{ccccc}
\hline Sampling zone & Period of landfilling & Landfilled wastes & Area $\left(\mathrm{m}^{2}\right) /$ Volume $\left(\mathrm{m}^{3}\right)$ & Remark \\
\hline $\mathrm{A}_{\text {total }}$ & $1992.02-2000.10$ & & \\
A1 & $1992.10-2000.7$ & & $4,090,000 / 2,510,000$ & Closed \\
A2 & $1993.03-1999.12$ & & & \\
A3 & $1993.06-1996.12$ & MSW $^{\mathrm{a}}$ & + & Operating \\
B $_{\text {total }}$ & $2000.10-$ & ISW $^{\mathrm{b}}$ & $4,090,000 / 2,480,000$ & \\
B1 & $2001.04-2007.2$ & & \\
B2 & $2004.01-2009.4$ & & \\
B3 & $2005.03-$ & & \\
\hline
\end{tabular}

${ }^{\mathrm{a}} \mathrm{MSW}$, municipal solid waste: food, paper, plastics, wood, rubber, leather, textiles, glass, metals, etc.

${ }^{\mathrm{b}}$ ISW, industrial solid waste: wood, plastics, paper, textiles, soil, brick, metals, glass, etc. 


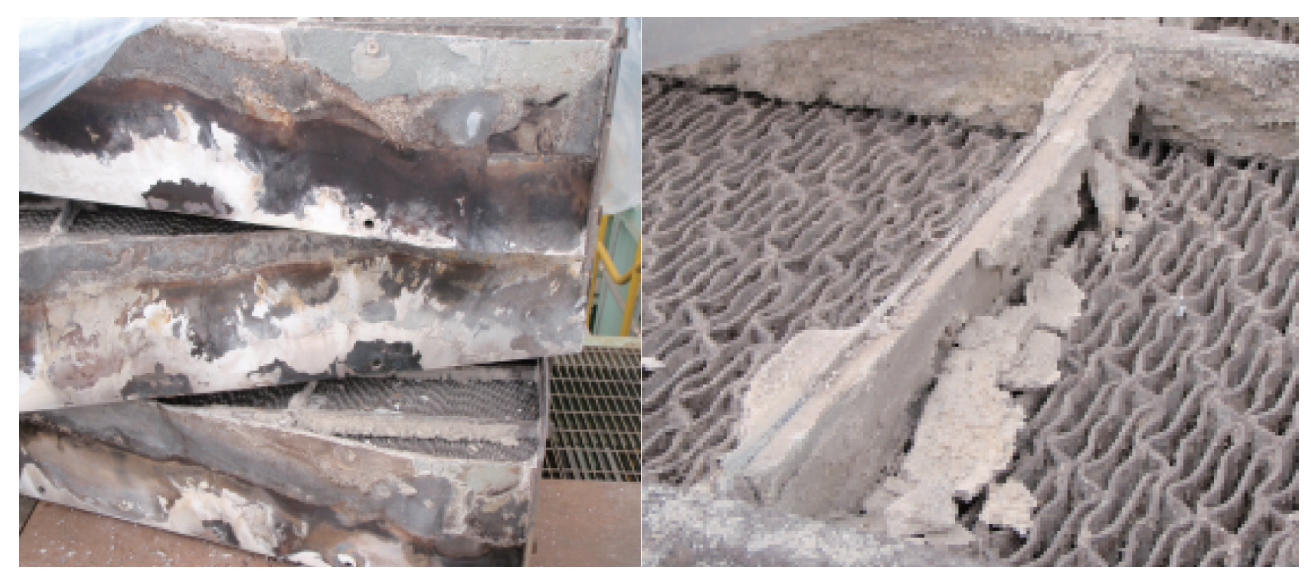

Fig. 2. Disaggregate gas air heater (GAH) and scale.

monia and hydrogen sulfide was determined as needed. Similar to $\mathrm{CH}_{4}, \mathrm{CO}_{2}$, ammonia, and hydrogen sulfide concentrations in zone A was under follow-up control and showed lower levels than those of zone B.

Table 3 shows the analysis of the siloxane results in LFG. The total siloxane concentration in LFG was $1.85-21.18 \mathrm{mg} / \mathrm{m}^{3}$ (mean, $7.95 \mathrm{mg} / \mathrm{m}^{3}$ ), which was similar to other studies (3-24

Table 2. Major landfill gas (LFG) components

\begin{tabular}{lcccc}
\hline & $\begin{array}{c}\mathrm{CH}_{4} \\
(\%)\end{array}$ & $\begin{array}{c}\mathrm{CO}_{2} \\
(\%)\end{array}$ & $\begin{array}{c}\mathrm{NH}_{3} \\
(\mathbf{p p m v})\end{array}$ & $\begin{array}{c}\mathrm{H}_{2} \mathrm{~S} \\
(\mathbf{p p m v})\end{array}$ \\
\hline $\mathrm{A}_{\text {total }}$ & 46.5 & 37.0 & 1,571 & 121 \\
$\mathrm{~A} 1$ & 54.0 & 36.0 & 971 & 121 \\
$\mathrm{~A} 2$ & 55.0 & 35.0 & 375 & 22 \\
$\mathrm{~A} 3$ & 16.0 & 22.0 & 3,514 & 111 \\
$\mathrm{~B}_{\text {total }}$ & 49.5 & 29.0 & 1,632 & 104 \\
$\mathrm{~B} 1$ & 39.0 & 37.0 & 2,507 & 891 \\
$\mathrm{~B} 2$ & 48.5 & 36.0 & 1,642 & 904 \\
$\mathrm{~B} 3$ & 57.0 & 39.0 & 1,850 & 1,211 \\
\hline
\end{tabular}

Table 3. Siloxane ${ }^{\text {a) }}$ concentration in landfill gas (LFG)

\begin{tabular}{lcccccccr}
\hline & L2 & L3 & L4 & L5 & D4 & D5 & D6 & Total \\
\hline $\mathrm{A}_{\text {total }}$ & & & & & 2.04 & 1.36 & 0.28 & 3.68 \\
$\mathrm{~A} 1$ & & & 0.08 & & 1.99 & 1.72 & 0.6 & 4.39 \\
$\mathrm{~A} 2$ & & & 0.05 & 0.19 & 1.99 & 1.91 & 0.56 & 4.69 \\
$\mathrm{~A} 3$ & & & 0.03 & & 0.93 & 0.69 & 0.21 & 1.85 \\
$\mathrm{~B}_{\text {total }}$ & 0.04 & & & & 4.93 & 2.27 & 0.61 & 7.85 \\
$\mathrm{~B} 1$ & 0.01 & & 0.41 & & 7.05 & 4.64 & 0.9 & 13.01 \\
$\mathrm{~B} 2$ & & & 0.08 & & 3.35 & 2.44 & 1.1 & 6.97 \\
B3 & 0.05 & 0.55 & 0.95 & 0.82 & 8.02 & 6.07 & 4.73 & 21.18 \\
\hline Average & 0.01 & 0.07 & 0.2 & 0.13 & 3.79 & 2.64 & 1.12 & 7.95 \\
\hline
\end{tabular}

Units: $\mathrm{mg}$ siloxane $/ \mathrm{m}^{3} \mathrm{LFG}$.

${ }^{a}$ L2: hexamethyldisiloxane, L3: oxtamethyltrisiloxane,

L4: decamethyltetrasiloxane, L5: dodecamethylpentasiloxane,

D4: octamethylcyclotetrasiloxane, D5: camethylcyclopentasiloxane, D6: dodecamethylcyclohexasiloxane. $\mathrm{mg} / \mathrm{m}^{3}$ ) [12]. Deviations can occur in the total LFG siloxane concentration by various factors such as temperature of the environment and in the landfill [19], but the ratio of siloxane by component shows that D4 and D5 has the highest level [15, 20, 21]. Result of this study also showed that siloxane concentration by component was highest at D4 (average, $3.79 \mathrm{mg} / \mathrm{m}^{3}$ ) and D5 (average, $2.64 \mathrm{mg} / \mathrm{m}^{3}$ ).

\subsection{Characteristics of the Scale in LFG Utility Facilities}

Fig. 2 shows the scale and disaggregate GAH for scale removal. As shown in Fig. 3, a large amount of the scale in the GAH appeared light grey or light yellow. As a result of the GAH scale analysis (Fig. 4), the major components were oxygen, sulfur, and iron; $\mathrm{Fe}_{2} \mathrm{O}_{3}$ was $38.5 \%$, and sulfur was $18.4 \%$. Hydrogen sulfide which was not removed but remained during the pretreatment process and moisture caused by the GAH heat riser combined to generate acidity. This acid reacted with iron in the GAH to cause $\mathrm{Fe}_{2} \mathrm{O}_{3}$ scale. It was discovered that the GAH scale was caused by sulfur gas (hydrogen sulfide).

Fig. 5 shows the scale inside the boiler. The interior of the boiler was coated with white or light grey scale, and white crystalline scale was found on the walls (Figs. 5 and 6). An analysis of the elemental and chemical composition of the scale collected from the walls and the bottom of the boiler are shown in Figs. 6 and 7 . Scale collected from the walls of the boiler appeared like cotton and was the immediate filamentous type as shown by SEM. The scale on the walls of the boiler was pure silica and silicon crystals, which were composed of oxygen and silicon. The SEM-EDS analysis indicated that the scale collected on the bottom of boiler was light grey and looked like a thorn. It had the second largest content of carbon, (the first largest was oxygen and silicon), and the needle-like silicon was determined to be an organosilicone, which was directly combined with carbon atoms.

The reason that silicon dioxide scale is generated inside a boiler is related to the low removal rate of siloxane during the pretreatment process at LFG utility facilities. The S landfill LFG utility use a representative siloxane removal method by absorption, adsorption, freezing, cooling, and chilling (Fig. 1) [12]. Impregnated activated carbon is used mainly as an absorbent, which is made from impregnated $\mathrm{KOH}$, to remove acidic gas such as hydrogen sulfide. Condensing water or moisture gen- 


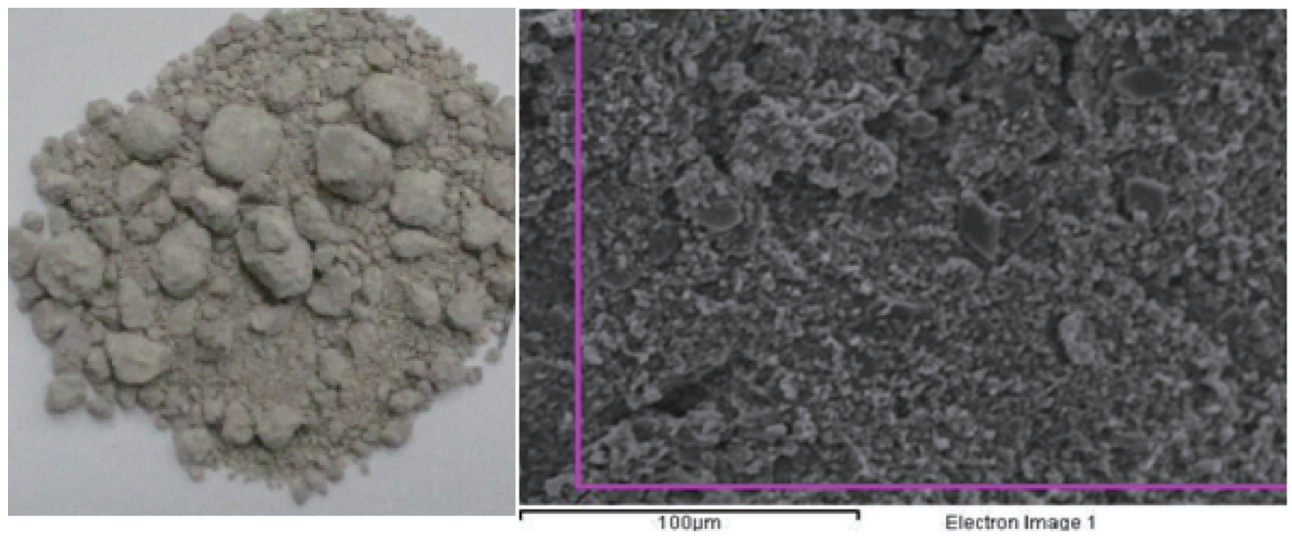

Fig. 3. Scale collected from gas air heater (GAH) and SEM analysis.

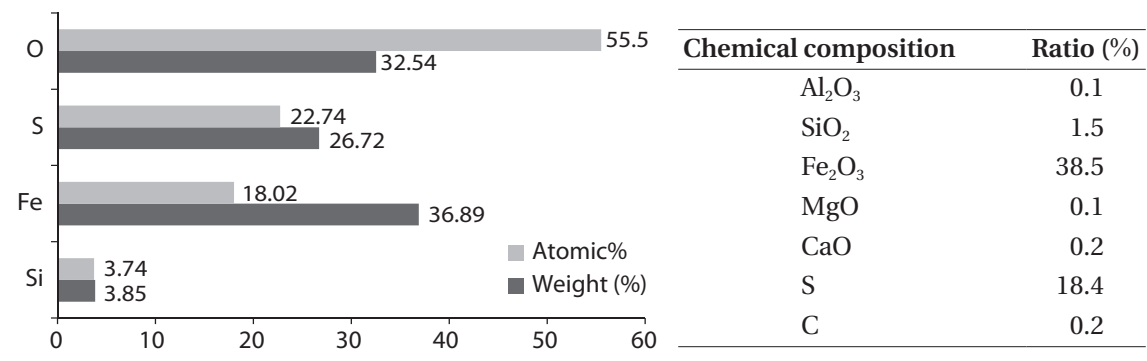

Fig. 4. Element and chemical composition of scale collected from gas air heater (GAH).
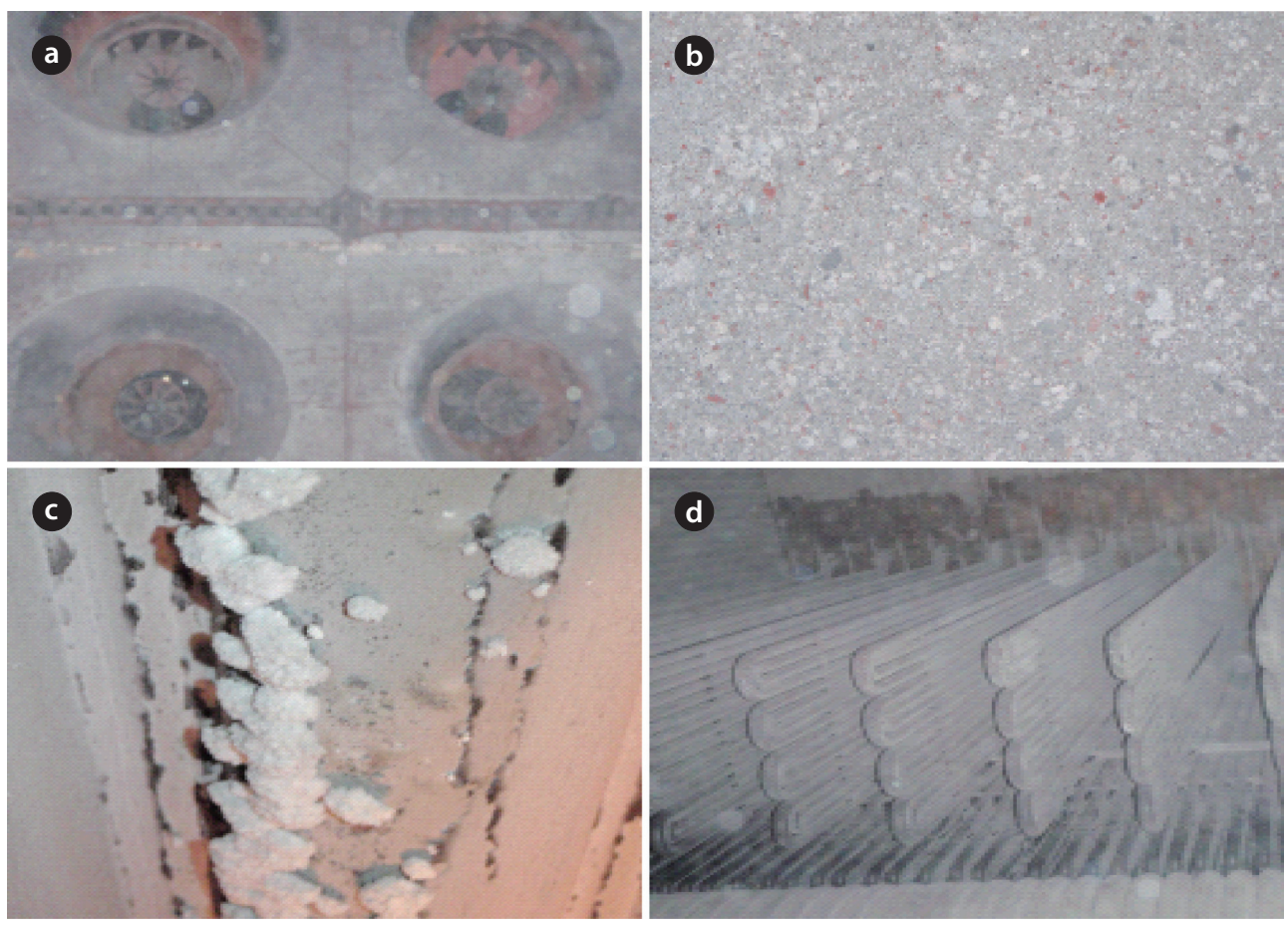

Fig. 5. Scales on the inner surface of boiler and the parts. (a) Entrance, (b) Bottom, (c) Wall, (d) Top. 

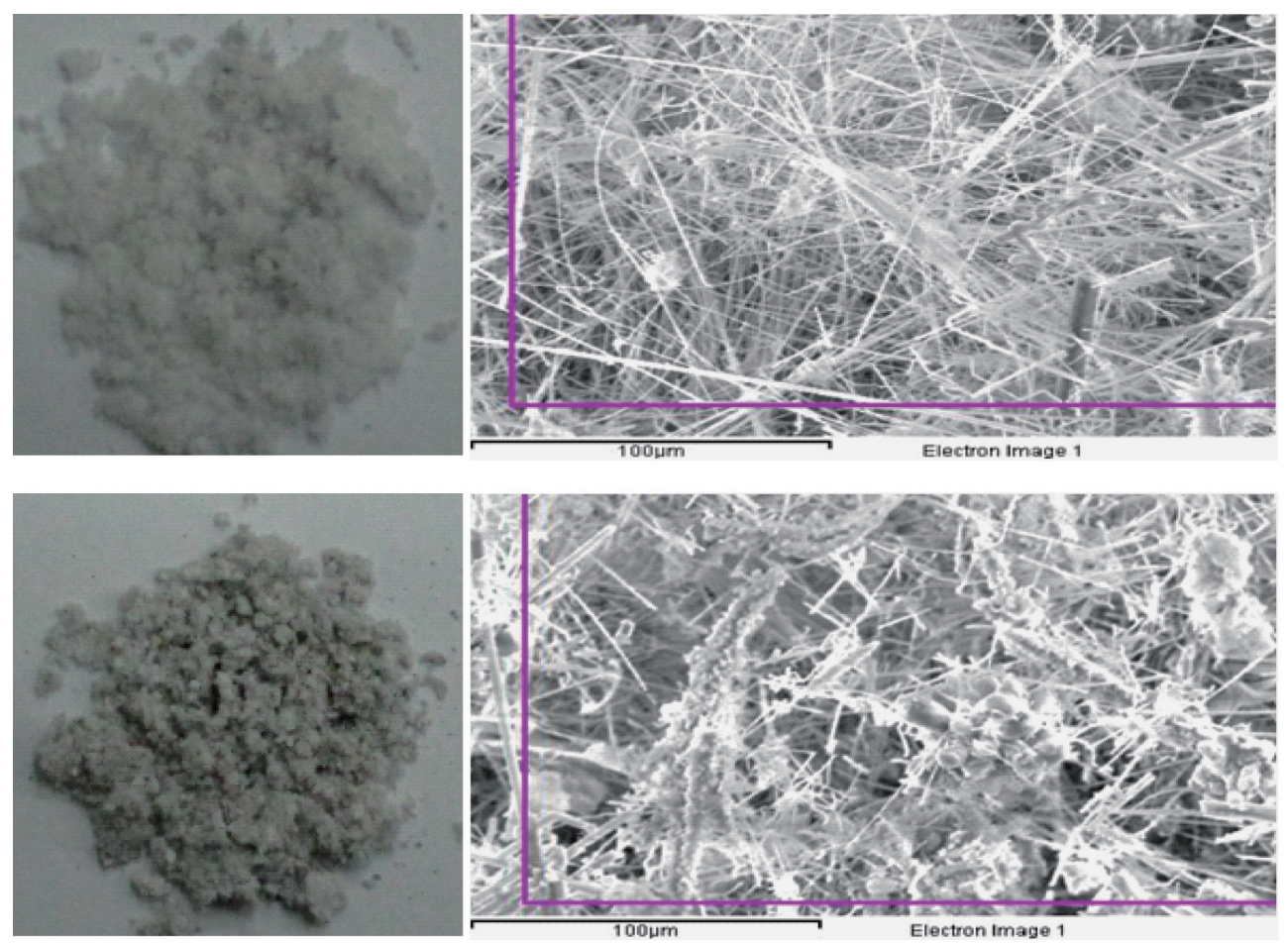

Fig. 6. Scales collected from the wall and the bottom of boiler and SEM analysis.

a

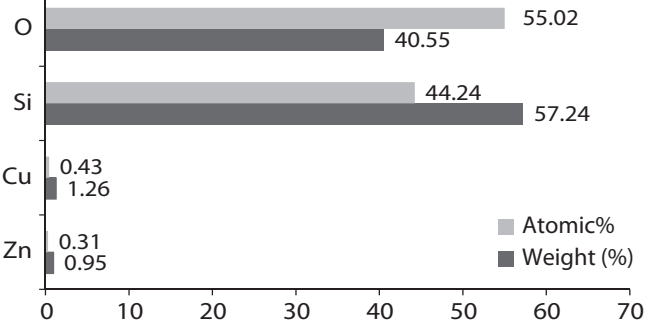

b

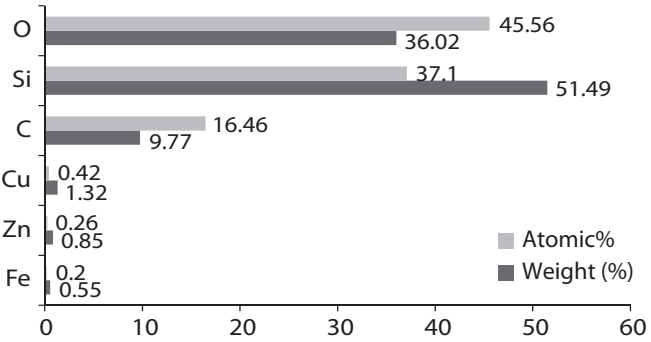

\begin{tabular}{cc}
\hline Chemical composition & Ratio (\%) \\
\hline $\mathrm{Al}_{2} \mathrm{O}_{3}$ & 0.1 \\
$\mathrm{SiO}_{2}$ & 98.8 \\
$\mathrm{Fe}_{2} \mathrm{O}_{3}$ & 0.4 \\
$\mathrm{C}$ & 0.1
\end{tabular}

\begin{tabular}{cc}
\hline Chemical composition & Ratio (\%) \\
\hline $\mathrm{Al}_{2} \mathrm{O}_{3}$ & 0.7 \\
$\mathrm{SiO}_{2}$ & 92.8 \\
$\mathrm{Fe}_{2} \mathrm{O}_{3}$ & 3.6 \\
$\mathrm{MgO}$ & 0.1 \\
$\mathrm{CaO}$ & 0.6 \\
$\mathrm{~S}$ & 0.1 \\
$\mathrm{C}$ & 0.2 \\
\hline
\end{tabular}

Fig. 7. Element and chemical composition of scales collected from the wall and the bottom of boiler. (a) Scale from the wall of boiler, (b) Scale from the bottom of boiler.

erated by the temperature and pressure differences during the process is different from nonpolar solvents such as methanol or acetone, which are effective for absorbing siloxane [8]. Therefore, some siloxane can be removed by absorption, but the removal efficiency of siloxane is poor during the pretreatment process that removes sulfur and moisture. It was determined that the siloxane that remained in the LFG at the pretreatment fa- cility was converted into silica and some silica-generated scale.

Silica scale caused by siloxane results in abrasion of equipment, lower heat transfer efficiency, and clogging of valves and exhaust gas pipes in utility facilities. Because the equipment exterior is overheated if silica scale becomes thicker, it is necessary to remove the siloxane in advance or remove the silica. Silica scale has a low density due to its compositional features. 
Therefore, it was determined that such scale was deposited in the sludge pipe at the bottom of the boiler and valve and blocked the flow stream. Heat conduction of LFG by combustion worsened due to the low heat conduction of silica itself and an inner air layer of quilt (quilting by hand) when scale was deposited on the wall of the boiler functioning as a heat sink. Repair cost for silica scale damage is approximately US $\$ 60,000$ per year based on a $1 \mathrm{MW}$ engine [22]. The target LFG utility facility in this study suffers a loss due to maintenance fees and boiler shutdown (12 days per time) caused by periodic removal of silica scale.

\section{Conclusions}

We examined the creation of LFG and the characteristics of hydrogen sulfide and siloxane generation occurring at $S$ landfill to investigate the effect of hydrogen sulfide and siloxane on LFG utility facilities. We also analyzed the scale components. The results we obtained are as follows:

1) As a result of analyzing LFG of the target $S$ landfill, hydrogen sulfide averaged 436 ppmv (range, 22-1,211 ppmv), and total siloxane concentration averaged $7.95 \mathrm{mg} / \mathrm{m}^{3}$ (range, 1.85 $21.18 \mathrm{mg} / \mathrm{m}^{3}$ ), which were similar to the general LFG composition range to satisfy $\mathrm{CH}_{4}$ concentrations for LFG utility facilities.

2) As a result of a scale analysis of the LFG utility facilities, the scale in GAH consisted mainly of $\mathrm{Fe}_{2} \mathrm{O}_{3}$ and the scale in the boiler consisted of $>98 \%$ silicon dioxide.

3) The GAH scale was caused by hydrogen sulfide corrosiveness, and the scale on the walls and the bottom of the boiler were incurred by siloxane combustion.

4) The compositional characteristics of the immediate filamentous type added to the thermal cutoffs of the silicon dioxide scale resulting in adverse impacts on LFG utility facilities such as heat blocks and clogging of major components and exhaust gas pipes.

\section{Acknowledgments}

This work was supported by the Power Generation \& Electricity Delivery of the Korea Institute of Energy Technology Evaluation and Planning (KETEP) grant funded by the Korea Government Ministry of Knowledge Economy (Development of Biogas Pretreatment Fuel System for 5MW-GT) (no. 2009T100200127).

\section{References}

1. Willumsen H. Landfill gas recovery plants: looking at types and numbers worldwide. Waste Manage. World 2004;JulAug:125-133.

2. Seo DC, Song SS, Won JC. Removal of volatile organic silicon compounds (siloxane) from landfill gas by adsorbents. J. Korean Soc. Environ. Eng. 2009;31:793-802.

3. Bove R, Lunghi P. Electric power generation from landfill gas using traditional and innovative technologies. Energy Convers. Manage. 2006;47:1391-1401.

4. Rasi S, Lehtinen J, Rintala J. Determination of organic silicon compounds in biogas from wastewater treatments plants, landfills, and co-digestion plants. Renew. Energy
2010;35:2666-2673

5. Hagmann M, Heimbrand E, Hentshcel P. Determination of siloxanes in biogas from landfills and sewage treatment plants. In: Proceedings of the 17th International Waste Management and Landfill Symposium; 1999 Oct 4-8; Cagliari, Italy. p. 483-488.

6. Hayes HC, Graening GJ, Saeed S, Kao S. A summary of available analytical methods for the determination of siloxanes in biogas. In: SWANA 26th Annual Landfill Gas Symposium; 2003 Mar 24-27; Tampa, FL. p. 24-27.

7. Shin HC, Park JW, Park K, Song HC. Removal characteristics of trace compounds of landfill gas by activated carbon adsorption. Environ. Pollut. 2002;119:227-236.

8. Kim NJ, Choi JM, Ji EJ. Solvent selection for the detection of siloxanes in landfill gas. J. Korean Soc. Environ. Eng. 2007;29:915-921.

9. Rasi S, Läntelä J, Veijanen A, Rintala J. Landfill gas upgrading with countercurrent water wash. Waste Manage. (Oxford) 2008;28:1528-1534.

10. Ohannessian A, Desjardin V, Chatain V, Germain P. Volatile organic silicon compounds: the most undesirable contaminants in biogases. Water Sci. Technol. 2008;58:1775-1781.

11. Dewil R, Appels L, Baeyens J. Energy use of biogas hampered by the presence of siloxanes. Energy Convers. Manage. 2006;47:1711-1722.

12. Ajhar M, Travesset M, Yüce S, Melin T. Siloxane removal from landfill and digester gas--a technology overview. Bioresour. Technol. 2010;101:2913-2923.

13. Kim JK, Choi HS, Yoo IS. Adsorption of the siloxane contained in landfill gas using clay mineral. J. Korean Ind. Eng. Chem. 2006; 17:465-470.

14. Tower P. Removal of siloxanes from landfill gas by SAGTM polymorphous porous graphite treatment systems. In: SWANA 26th Annual Landfill Gas Symposium; 2003 Mar 24-27; Tampa, FL. p. 1-5.

15. Jeong SR, Park JK, Hur KB, Lee CY, Lee NH. Characteristics of siloxane concentrations in landfill gas. J. Korean Soc. Waste Manage. 2010;27:356-362.

16. Saeed S, Kao S, Graening G. Comparison of impinger and canister methods for the determination of siloxanes in air. In: AWMA Symposium on Air Quality Measurement Methods and Technology; 2002 Nov 13-15; San Francisco, CA.

17. Song SH, Eom CY, Hur KB, Lee NH, Lee CY. Characterization of siloxane concentrations in anaerobic digestion gas of organic wastes. J. Korean Soc. Waste Manage. 2010;27:348-355.

18. Air Toxics Ltd. Siloxanes by GC/MS: introducing the Air Toxics Ltd. method. In the Air 2002;7:1-3.

19. Song SS. Characterization and adsorptive removal methods of siloxanes in landfill gas [dissertation]. Incheon: Inha University; 2009.

20. Seo DC, Yun SK, Kim MJ, et al. Determination of organic silicon compounds (siloxane) in landfill gas. J. Korean Soc. Waste Manage. 2007;24:391-399.

21. Wheless E, Pierce J. Siloxanes in landfill and digester gas update. In: SWANA 27th Annual Landfill Gas Symposium; 2004 Mar 22-25; San Antonio, TX.

22. Tower P. New technology for removal of siloxanes in digester gas results in lower maintenance costs and air quality benefits in power generation equipment. In: WEFTEC 78th Annual Technical Exhibition and Conference; 2003 Oct 11-15; Los Angeles, CA. p. 2-8. 